\title{
Minimizing the Congestion Index and Mode Share of Traffic Congestion in Urban Area
}

\author{
Norisma Idris \\ Social Science and Liberal Arts, UCSI University, Malaysia \\ Idris667@hotmail.com
}

\author{
Article Info \\ Journal of Journal of Enterprise and Business Intelligence (http://anapub.co.ke/journals/jebi/jebi.html) \\ Doi: https://doi.org/10.53759/5181/JEBI202202004 \\ Received 20 June 2021; Revised form 12 August 2021; Accepted 18 October 2021. \\ Available online 05 January 2022. \\ (C2022 Published by AnaPub Publications.
}

\begin{abstract}
Urbanization is heavily influenced by the transportation that becomes fundamental to the mobility of human activities. However, unchecked growth in transportation raises serious concerns about many issues such as congestions, limited parking, and public transit problem. This phenomenon also overwhelms Kuala Lumpur, the capital city of Malaysia that has a high number of car ownership. Consequently, traffic congestion in urban area has affected people living there in terms of lost time on the road and waste of fuel consumption. In this regard, this research aims to minimize the congestion index and mode share in Kuala Lumpur based on the tested of six travel demand strategy variables. The problem was model and optimized using system dynamics (SD) optimization approach. Results of the developed SD optimization model shows that the optimized congestion index is 0.89863 while the mode share is $52.87 \%$ in 2030 compared to SD baserun which are only 1.1021 and $21.7 \%$ for congestion index and mode share respectively. This finding shows that SD optimization performed a better result in terms of achieving the targeted of congestion index and mode share of <0.6 and 50\% by 2030 compared to SD baserun. From the managerial perspective, this research helps towards achieving the government's congestion index and mode share targets through strategizing the ways on attracting public transportation and discouraging the usage of private cars in Kuala Lumpur.
\end{abstract}

Keywords - Congestion index; Mode share; Public transportation; Urban area; System dynamics Optimization.

\section{INTRODUCTION}

The urban traffic congestion had worsened in many countries today as a result of increase in population, economic growth, private vehicle ownership, urbanization, housing development, and jobs opportunity [1]. The congestion phenomenon is striking for most of the developing cities at which the rate of vehicle fleet growth greatly offset the rate of growth of transportation facilities [2]. Congestion undoubtedly, causes road users to experience unavoidable delay due to large volumes of drivers utilizing the roads in the same period of time; adding extra time to arrive at work and comes with its highly cost. For example, 0.8 billion of hours and 0.3 billion more gallons of fuel are wasted in United States in 2020 due to congestion issue [3]. In fact, traffic congestion has also surface many Asian cities today due to its high growth density of population and rapid growth of motorization [4] including the cities in Malaysia.

The capital city of Malaysia, Kuala Lumpur is expected to grow up to 10 million residents by 2020 [5]. In 2017, the city has reached almost thirteen million number of vehicles on the road which constitutes 98 percent of the private vehicles' trips per day [6]. The cause of heavy traffic congestion in Kuala Lumpur is due to the high dependency on private vehicle and low usage of public transportation [7]. Moreover, with scarce area of land in the city that limits the growth of road infrastructure with the increasing demand in mobility will worsen the traffic congestion. The government has also made an initiative to improve the imbalance mode share between public transportation and private vehicles and aim to achieve 50\% public transportation mode share by 2030 [8]. It is found that early urban transport studies emphasized on improving the traffic management and infrastructures which include constructing new roads and widening the existing one in combating congestion in Kuala Lumpur [9]. However, the efforts did not resolve the problem but create more congested roads in the city as the accessibility of new roads attracts more travellers [10]. Thus, under the National Key Result Area, the government has focused improvement in the investment of public transportation infrastructures to raise its mode share added that the expansion of roads is constrained by limited space in inner areas of Kuala Lumpur [11].

In this regard, this research aims to mitigate the traffic congestion in Kuala Lumpur by optimizing the congestion index and mode share outputs using system dynamics (SD) optimization approach. Level of service (LOS) is one of 
the measure for congestion index, that is defined as the ratio of the volume vehicles on road divides by its vehicle's road capacity [12]. The bigger the ratio of congestion index as it approaches 1.00 , the more congested the road condition would be [13]. Comparatively, mode share is defined as the percentage of trips made by travellers to commute to their destination via transportation mode [14]. A set of congestion mitigation strategies that consists of six strategy variables were experimented to observe the impact of tested variables on the output of congestion index and mode share. Detail explanations on the SD optimization is further elaborated in the following section. It is continued by the explanation on the related results and conclusion section. Finally, the future work will end the paper's section.

\section{Model Framework}

\section{METHODOLOGY}

In this research, the aim is to develop an optimization model with dynamic feature that would help to minimize the level of congestion given the current condition of road supply and travel in Malaysia. The modelling process starts by the development of system dynamics (SD) model that composed of four interconnecting components that are traffic supply, travel demand, traffic system and mode share. The model simulates the future condition of traffic congestion underlying the interactions of these different components input named strategy intervention. The interactions of the components that construct the function of congestion is shown in Figure 1. Referring to the figure, the system boundary is the endogenous variables whereas outside it is the exogenous variables. To decide whether to undertake a trip by public transport or not, travellers are influenced by a number of attributes of public transportation which includes travel time, travel cost and accessibility.

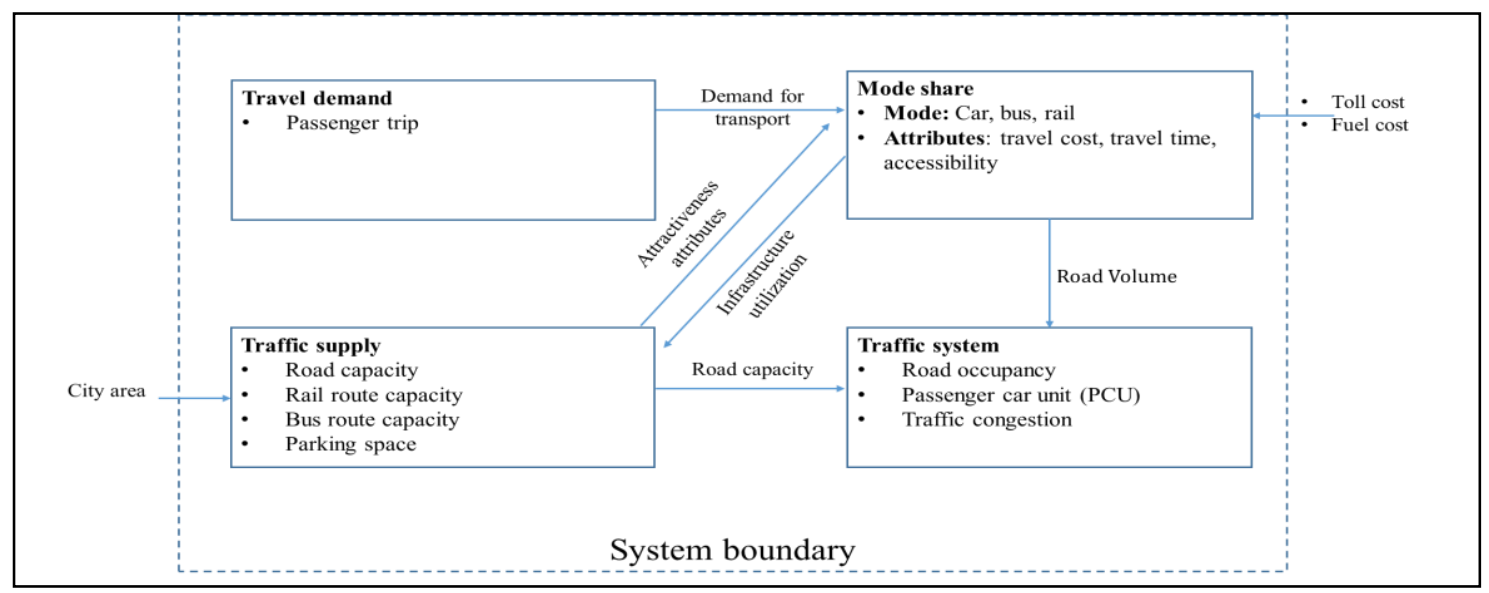

Fig 1. The framework of transportation model

The information on the traffic volume behavior which shows an increasing trend is highlighted in Figure 2. This trend is expected to be increase in the incoming years [15]. This paper will address on which combinations of travel demand strategies that helps to achieve a decline growth of the public transportation trend in the future.

\section{Data Collection}

Data collection is one of the important process in any research. In this research, only secondary data was utilized to accomplish the work. Secondary data were taken from various reports published that are related to transportation sector. The main documents used are: (1) Kuala Lumpur City Draft Plan; (2) Highway Capacity Manual, and (3) Road Traffic Volume and other documents published by Jabatan Kerja Raya (JKR). Besides that, sources of secondary data includes historical data and reference mode that captured through local transportation literatures [16] and transportation related websites [17].

\section{Modelling Process with Variables Selection}

In this section, the process of how the model was developed and optimised were discussed. The process starts by the development of a dynamic model using system dynamics (SD) method with Vensim ${ }^{\mathrm{TM}}$ software. Then, the process continue with the optimization analysis using the policy optimization module in the software. The optimization function was used to improve the traffic congestion index and mode share by optimizing the value of six tested strategy variables which are bus route expansion rate, rate of park and ride $(\mathrm{P} \& \mathrm{R})$, rail travel cost, bus fare subsidies, 
rail construction rate and car parking charges. The description of each strategy variables is elaborated in Table 1.

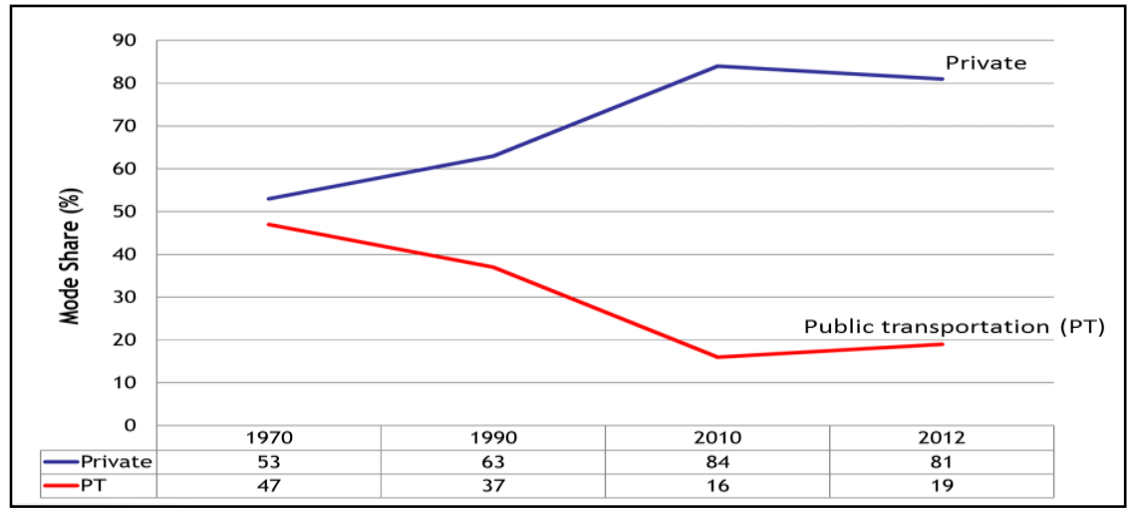

Fig 2. Trend of mode share for public transportation and private transportation [18]

Table 1. Description of the selected strategy variables

\begin{tabular}{|c|c|}
\hline Strategy variables & Description \\
\hline 1. Rail construction rate & The rate at which construction of rail infrastructure takes place. \\
\hline 2. Bus route expansion rate & The rate at which construction of bus infrastructure takes place. \\
\hline 3. Car parking charges & Car park charges per day. \\
\hline 4. Rate of $P \& R$ construction & The increase rate in park and ride facilities. \\
\hline 5. Rail travel cost & The average cost of using rail per trip \\
\hline 6. Bus fare subsidies & The portion of subsidies that government supports on bus fare \\
\hline
\end{tabular}

Theoretically, SD optimization was used as a medium of experimentation to understand the behavior of targeted variables of congestion index and mode share for intervention purpose [19]. Referring to the model, the optimization was run in year 2017 to observe the changes in congestion index and mode share by the year 2030. Generally, there are five steps to execute the SD optimization process. Figure 3 shows the steps which is adapted from the study by [20].

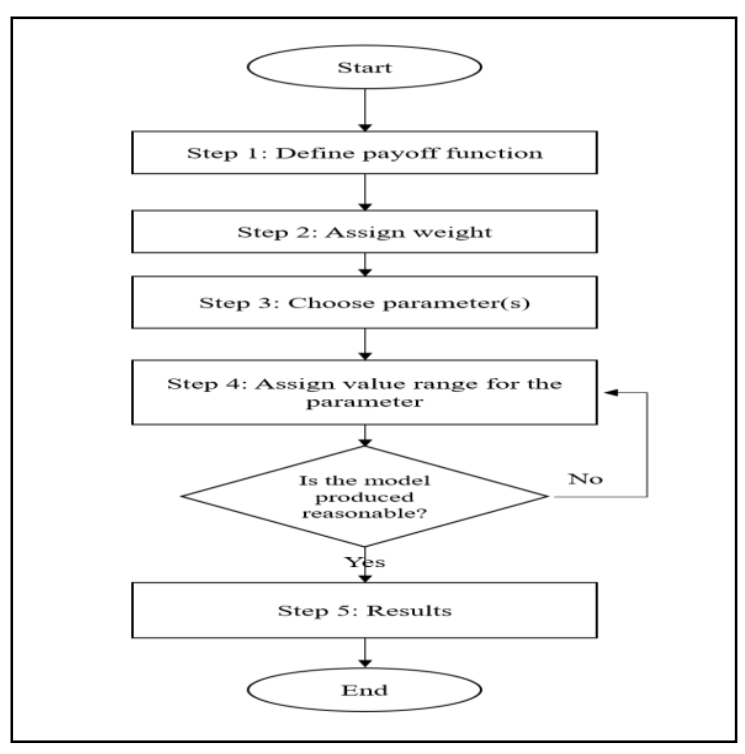


Fig 3. Workflow of the SD optimization process

The SD optimization model analysis was set to start by year 2017. The payoff function was determined during the first stage while weight of the objective function was assigned during the second stage to -1.0. Since the objective function was to minimize the congestion level, the weights is set to negative when less is better [4]. The model's parameter(s) was chosen in third stage since the weighted payoff will attempt to minimize the objective function. Later, a range for the each selected parameters were defined (see Table 1 for the list of variables). The optimization process continues by searching for the best solution and displays the results. The optimization process occurs by maximizing the payoff function in order to minimize the congestion index until year 2030. The objective function for the optimization is shown in equation below.

Objective function $=$ Min $\mid$ Congestion index ${ }_{2030} \mid$

Causal Loop Diagram of Transportation Model

In SD, causal loop diagram (CLD) is a tool used to map out the working mechanism of the system as well to show the relationship and feedback of the interrelated variables [21]. The objective of the CLD is to explain the interrelation between road demand and road supply contributes to the increasing level of traffic congestion in Kuala Lumpur. In this research, four CLD's have been developed which will be explain in the following section.

\section{Loop 1: Road Construction Loop}

Road is constructed due to the demand of road user, when the traffic volume reaches the capacity, government would invest to expand the available roads. Construction of roads involved time delay as it requires some time for completion. Once the road is ready to use, the road capacity availability attracts more travelers to use the road. This will cause the number of traffic volume to increase, and government will need to decide on constructing more new roads. The phenomenon in traffic studies is known as the Downs Thomson paradox [22]. The phenomenon occurs when more new roads are build, more travelers will occupy the new roads as the attractiveness increases. Commonly the expansion of road increase in traffic volume increase at an exponential trend.

The CLD of the congestion spiral is presented in Figure 4. The positive symbol in the figure shows positive relationship between variable, while the negative symbol shows negative relationship between variables. Loop B1 shows the construction of road to increase road capacity has helps to reduce travel time of vehicle. This is because the road capacity can now occupy more vehicle without causing delay. Loop B2 shows that the increase in traffic volume will increase the travel time. This causes the attractiveness of using car decreases, as they need to spend more time travelling and divert them to using other mode of transportation. Thus, reduces the number of cars on road and traffic volume.

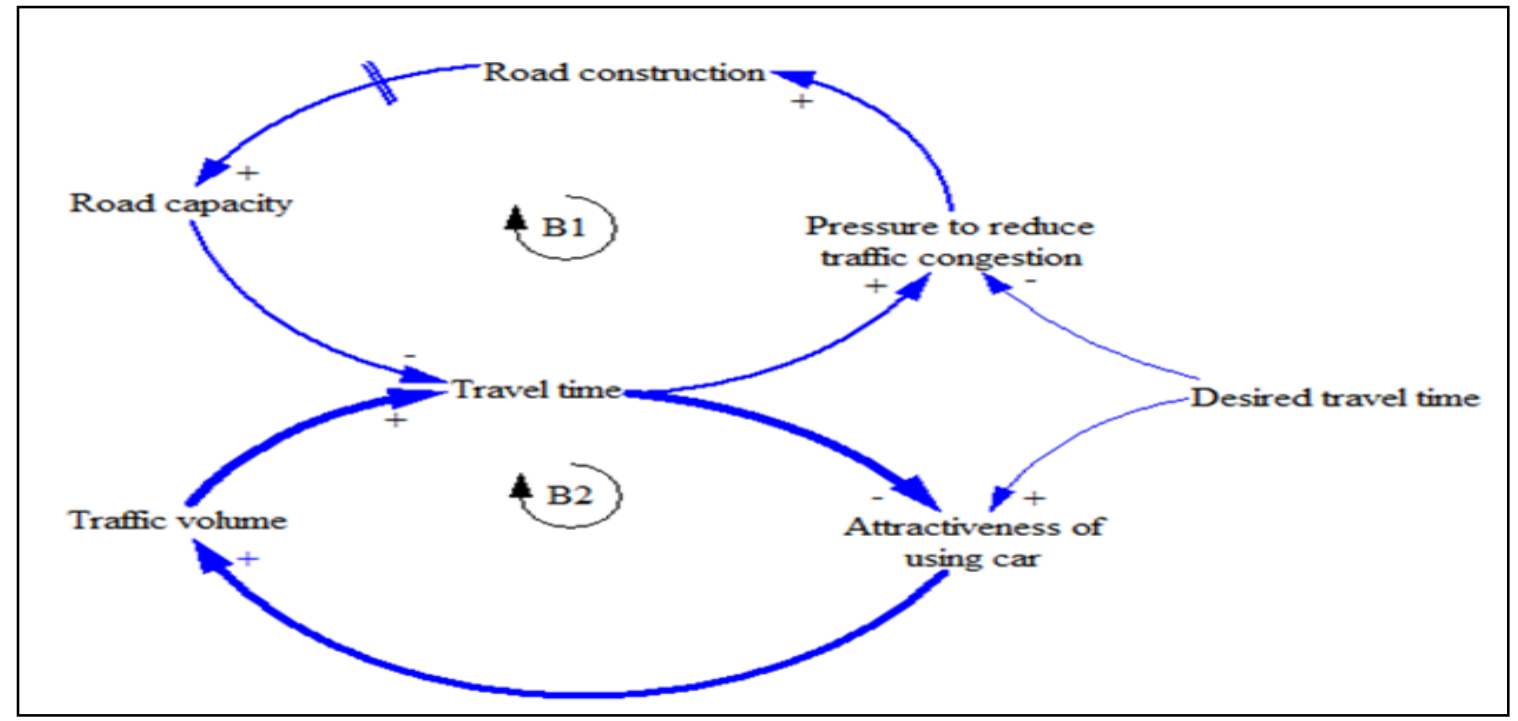

Fig 4. Causal loop diagram on the usage of public transportation and private vehicle

Loop 2: Parking Space Crowding Loop 
Parking space crowding loop represents the reduction in parking space that hinders the use of private vehicles. The parking overcrowding is causes by too many commuters that uses cars to travel to their destinations. When the number of cars increases, the cars per parking space increases denotes by the positive symbol in Figure 5. Thus, cars need more time in finding the parking spaces and this will increase the travel time compared using other transportation modes. This scenario is represented by balancing loop B1. The government has also enacted that cars are forbid from parking on street, this reduces the availability of parking and car user need to search for parking at other places. Consequently, this will reduce the attractiveness of using private vehicles as the expected travel time is relatively large. The reinforcing loop is shown by loop R1. Loop R2 is a reinforcing loop which shows that the increase in car user, will encourage the construction of desired parking spaces. The construction of parking increases the number of parking spaces and decrease the ratio of cars per parking spaces. Low number of parking spaces gives a lower searching time to find parking which helps to reduce the car travel time. Reduce in car travel time, increases the attractiveness of using car and consequently, increases the number of car user.

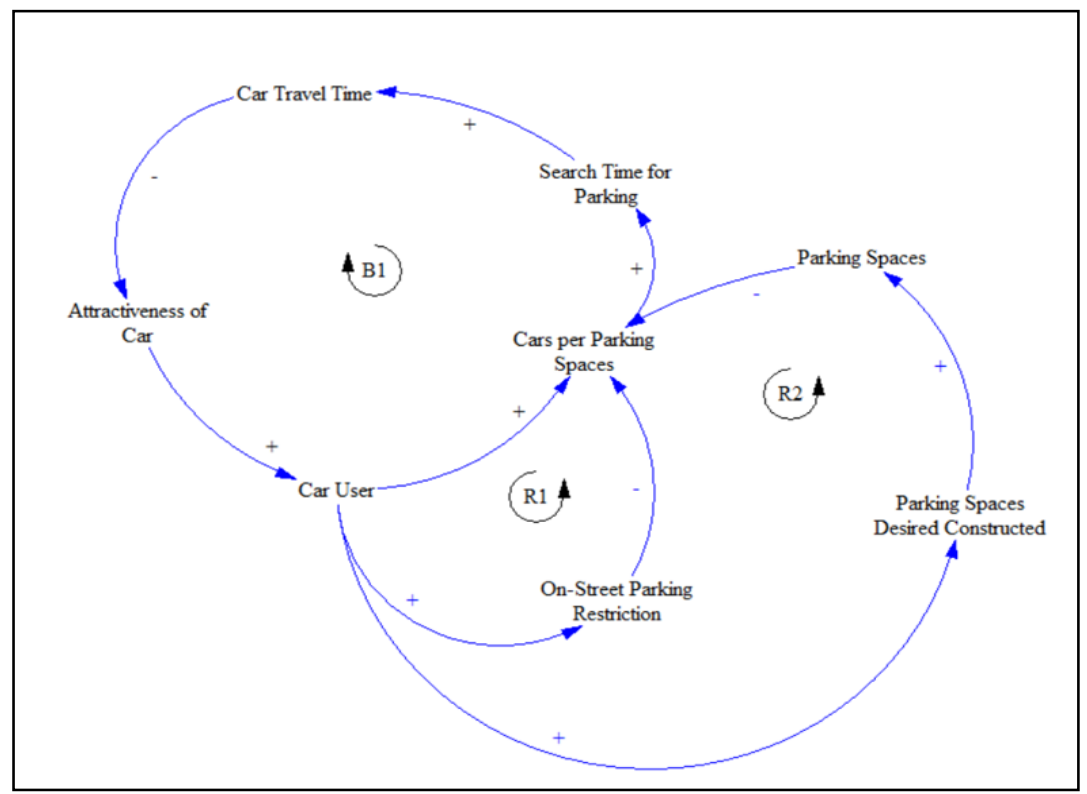

Fig 5. Causal loop diagram of parking crowding space

Loop 3: Public Transportation Vicious Cycle Loop

Increasing in the number of public transportation user will generate higher revenue for public transportation provider. The revenue generated from the usage can be used as investment to improve the current public transportation facilities. Loop R1 and loop R2 in Figure 6 explains that the more people that choose to ride public transportation, the higher the revenue available that in turns increases the capability of service provider to increase the public transportation facilities. As more public transportation supply is provided to the community, this will increase attractiveness in terms of accessibility, travel time and travel cost. The loop happens for both bus and rail transportation. However, increase in public transportation user, will increase the user per seat, which hinders the accessibility of commuters to ride the public transportation. Consequently, when the public transportation are too occupied, it becomes less attractive. This is shown both in loop B1 and loop B2 for bus and rail respectively. Loop R3 and loop R4 is a reinforcing loop. In loop R3, increase in attractiveness of bus, decrease the attractiveness of using car; vice versa, increase in attractiveness of using car, reduces the attractiveness of using bus. Similarly for loop R4, Increase in attractiveness of using car, reduces the attractiveness of using rail; vice versa, increase in attractiveness of using rail, will reduce the attractiveness of using car. 


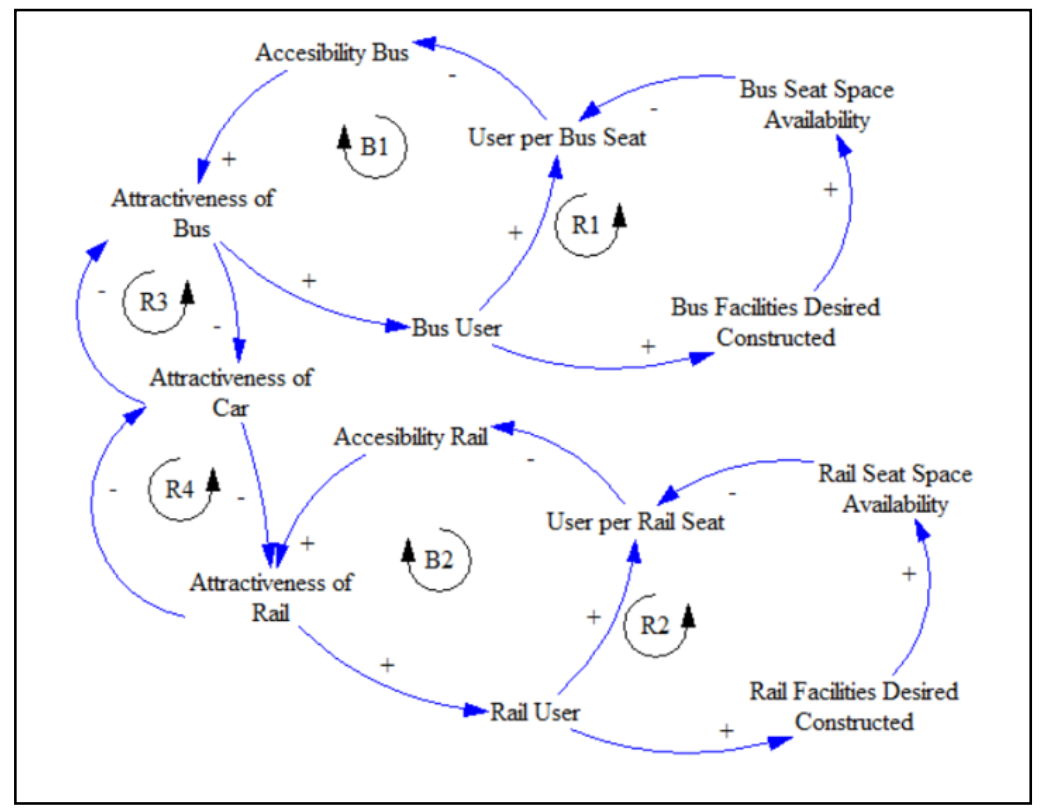

Fig 6. Causal loop diagram of public transportation vicious cycle

Loop 4: Travel Speed loop

The travel speed loop represents the long-term effects of the travel speed on attractiveness of using vehicle caused by traffic congestion. Loop B1 shows that the travel speed of vehicles on road depends on the road occupancy. The higher the road occupancy, the lower the travel speed of vehicle, which is illustrated by the negative symbol in Figure 7. Travel speeds corresponds to travel time of vehicle, which consequently hinders the attractiveness of vehicle. Vehicle attractiveness determines the number of vehicle user on the road. The scenario is presented as a reinforcing loop R2 shown in the Figure 7.

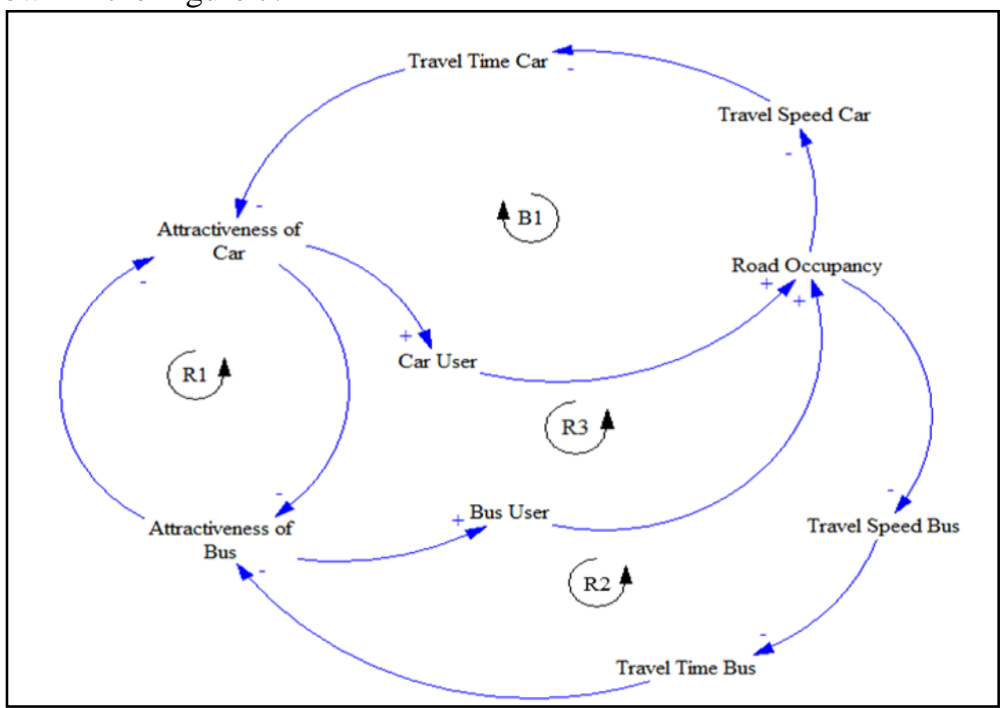

Fig 7. Causal loop diagram of travel speed

\section{RESULT AND DISCUSSION}

The results of the optimized value for the chosen variables targeted to minimize the traffic congestion index and mode share is presented in Table 2. The optimized values were compared with the baserun value, i.e., the initial output from simulation run without any alteration. 
Table 2. Result of optimized and baserun values for six strategy variables

\begin{tabular}{llll}
\hline Variables & Base run & Optimized Value & $\begin{array}{l}\text { Percentage } \\
\text { difference }\end{array}$ \\
\hline 1. Bus route expansion (1/year) & 0.0342 & 0.1123 & -228.3626 \\
2. Rate of P\&R construction (1/year) & 0.144 & 0.144 & 0 \\
3. Rail travel cost (RM) & 8 & 7.5278 & 5.9025 \\
4. Bus fare subsidies (\%) & 0.0737 & 0.07361 & 0.1221 \\
5. Rail construction rate (1/year) & 0.046 & 0.063 & -36.9565 \\
6. Car parking charges (RM) & 9 & 9 & 0 \\
\hline
\end{tabular}

According to the Table 2, the rate of bus route expansion shows the highest percentage difference, i.e., 228.3626 per cent which indicates as the most influential strategy to mitigate congestion in Kuala Lumpur.

The bus route expansion should be increased to 0.1123 per year. Moreover, the rail construction rate appears as the second highest percentage difference, i.e., 36.9565 per cent with optimized value 0.063 per year. On the other hand, the rail travel cost should be reduced to RM7.5278 while bus fare subsidies should be reducing to 0.07361 with minor reduction of 0.1221 per cent. In contrast, car parking charge and rate of P\&R construction should be maintained as initial value, which is RM 9 and 0.144 per year, respectively.

The changes in behaviour trend of congestion index when the six variables were optimized was shown in Figure 8. It is observed that trend of congestion index is slightly lower when the SD optimization is applied on these variables. In year 2030, the congestion is expected to reduce until 0.89863 . However, the SD optimization did not achieve the target of congestion level lower than 0.6. Besides, Figure 9 shows an increasing trend of public transportation mode share, which is the relational to the reduce level of congestion index. Similarly, Table 3 presents the respective values of congestion index and mode share in 2030.

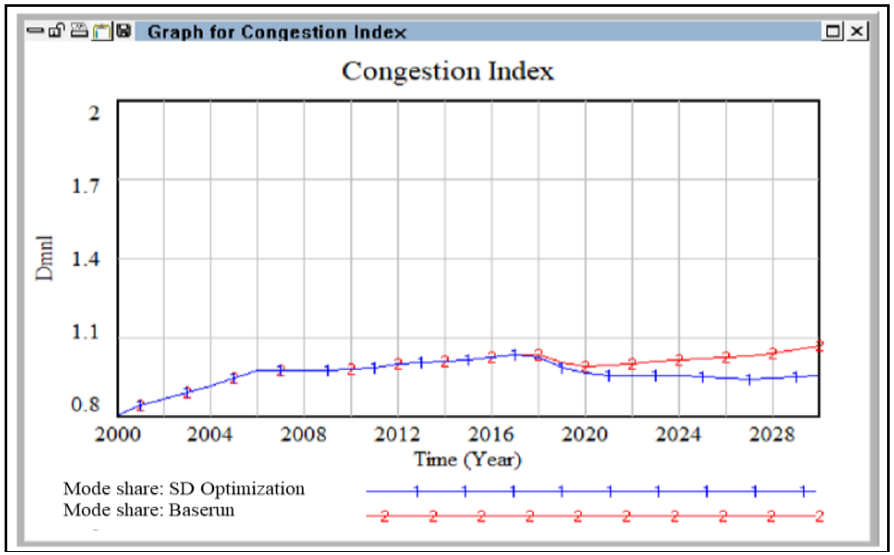

Fig 8. The congestion index trends from SD optimization

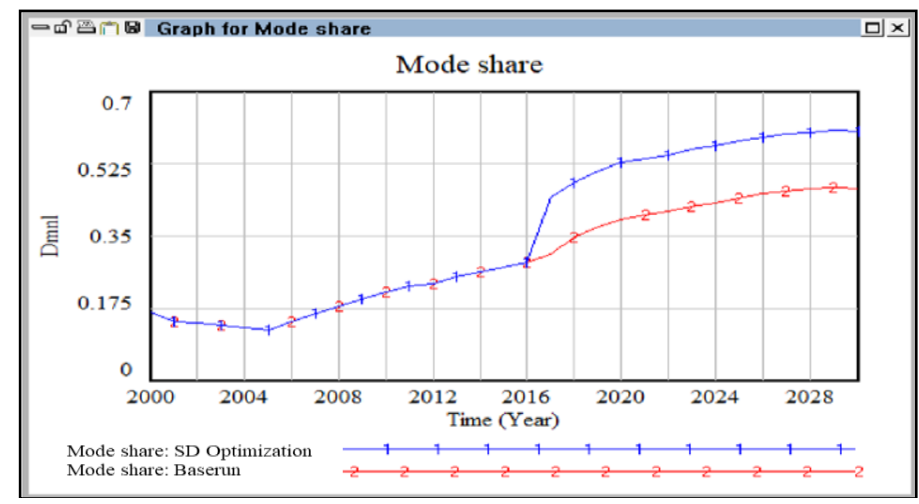

Fig 9. The public transportation mode share trends from SD optimization 
Table 3. Mode share and congestion index output values in 2030 based on SD optimization

\begin{tabular}{lll}
\hline Variables & SD Optimization & SD Baserun \\
\hline Mode Share (\%) & 0.52872 & 0.217 \\
Congestion Index & 0.89863 & 1.1021 \\
\hline
\end{tabular}

Results from the SD optimization model gives the optimal value for a mode share of public transportation which is $52.87 \%$. This exceeds the government's target to achieve a mode share of $50 \%$ by the year 2030 [22]. However, result from SD optimization analysis shows that the congestion index in Kuala Lumpur is 0.8963 in 2030. The congestion index that shows a value lower than 0.6 represents a free- flow traffic condition, in which drivers are virtually independent of others in a traffic stream. This gives options to drivers choosing desired speed and maneuver within the traffic flow [16]. Unfortunately, result from our SD optimization analysis shows the targeted congestion index $<0.6$ value is not achievable due to the highly non-linear spaces in the transportation modelling that causes the best value to be trapped in a local minima [11], [1]. Moreover, the many rules and constraints bounded within the transportation system effects the search of the best value in the solution space [15], [12].

\section{CONCLUSION \& FUTURE WORK}

In this paper, the optimization modelling process to minimize the transportation's congestion index and mode share in the urban area in Malaysia has been discussed. The modelling process starts with the development of a dynamic transportation model followed by the optimization analysis using SD policy optimization. Finding from this study highlighted the two important points: Firstly, SD optimization model gives a better result in terms of achieving the targeted 50\% of mode share and <0.6 value of congestion index compared to SD baserun. Secondly, the analysis shows that the mode share target can be achieve, while the congestion index will be unsuccessfully to be achieve in year 2030 due to many related reasons. With that, it can be concluded that SD optimization may not be effective due to its limitation to handle many variables in finding the optimal value of traffic congestion. Thus, a search for an Optimal Set Of Effective Strategies Can Be Executed Through Integration Of Sd With Another Optimization Method. This is one of the gap that can be further research in future. Furthermore, it would not be complete by merely suggesting the value of strategy variables without giving the detail cost of each implementation. Therefore, further research by incorporating cost benefit analysis is worth mentioning. Policy makers can choose the best strategies given a cost constraint, which is more practical in real world.

\section{References}

[1]. F. Cevallos and X. Wang, "ADAMS," Transportation Research Record: Journal of the Transportation Research Board, vol. 2063, no. 1, pp. 43-51, Jan. 2008.

[2]. C. Chen, K. Petty, A. Skabardonis, P. Varaiya, and Z. Jia, "Freeway Performance Measurement System: Mining Loop Detector Data," Transportation Research Record: Journal of the Transportation Research Board, vol. 1748, no. 1, pp. 96-102, Jan. 2001.

[3]. M. Deeshma and A. Verma, "Travel time modeling for bus transport system in Bangalore city," Transportation Letters, vol. 7, no. 1, pp. 47-56, Oct. 2014.

[4]. F. Ju, J. Zhang, and Q. Zhang, "Vertical transportation system of solid material for backfilling coal mining technology," International Journal of Mining Science and Technology, vol. 22, no. 1, pp. 41-45, Jan. 2012.

[5]. C. Quiroga, R. Pina, K. Hamad, and E. Kraus, "Intelligent Transportation System Spatial Data Modeling," Transportation Research Record: Journal of the Transportation Research Board, vol. 1972, no. 1, pp. 94-104, Jan. 2006.

[6]. S. Wang and V. Vaze, "Modeling Probability Distributions of Primary Delays in the National Air Transportation System," Transportation Research Record: Journal of the Transportation Research Board, vol. 2569, no. 1, pp. 42-52, Jan. 2016.

[7]. R. Shankar, R. Gupta, and D. K. Pathak, "Modeling critical success factors of traceability for food logistics system," Transportation Research Part E: Logistics and Transportation Review, vol. 119, pp. 205-222, Nov. 2018.

[8]. M. E. C. Bağdatli and A. Ş. Dokuz, "Modeling discretionary lane-changing decisions using an improved fuzzy cognitive map with association rule mining," Transportation Letters, vol. 13, no. 8, pp. 623-633, Apr. 2021.

[9]. M. Taamneh, S. Alkheder, and S. Taamneh, "Data-mining techniques for traffic accident modeling and prediction in the United Arab Emirates," Journal of Transportation Safety \& Security, vol. 9, no. 2, pp. 146-166, Apr. 2016.

[10]. A.Haghani, S. Y. Lee, and J. H. Byun, "A system dynamics approach to land use/transportation system performance modeling Part I: Methodology," Journal of Advanced Transportation, vol. 37, no. 1, pp. 1-41, Sep. 2003.

[11]. N. Schmidt-Polończyk, "Computer modeling of a fire hazard and evacuation of transportation tunnels with longitudinal ventilation system," AGH Journal of Mining and Geoengineering, vol. 37, no. 1, p. 93, 2013.

[12]. A.Battista and D. Ni, "Modeling Small Unmanned Aircraft System Traffic Flow Under External Force," Transportation Research Record: Journal of the Transportation Research Board, vol. 2626, no. 1, pp. 74-84, Jan. 2017.

[13]. J. Cai and Y. Liang, "System Dynamics Modeling for a Public-Private Partnership Program to Promote Bicycle-Metro Integration Based on Evolutionary Game," Transportation Research Record: Journal of the Transportation Research Board, p. 036119812110124 , May 2021.

[14]. ASiddiqui, "Modeling Construction Project-Induced Freight Reliability for South Carolina's Interstate System," Transportation Research Record: Journal of the Transportation Research Board, vol. 2673, no. 1, pp. 154-163, Jan. 2019. 
ISSN: 2789-5181

[15]. A.Battista and D. Ni, "Modeling Small Unmanned Aircraft System Traffic Flow Under External Force," Transportation Research Record: Journal of the Transportation Research Board, vol. 2626, no. 1, pp. 74-84, Jan. 2017.

[16]. J. Cai and Y. Liang, "System Dynamics Modeling for a Public-Private Partnership Program to Promote Bicycle-Metro Integration Based on Evolutionary Game," Transportation Research Record: Journal of the Transportation Research Board, p. 036119812110124, May 2021

[17]. W. Y. Szeto, "Dynamic Modeling for Intelligent Transportation System Applications," Journal of Intelligent Transportation Systems, vol. 18, no. 4, pp. 323-326, Aug. 2013.

[18]. K. Wei and V. Vaze, "Modeling Crew Itineraries and Delays in the National Air Transportation System," Transportation Science, vol. 52, no. 5, pp. 1276-1296, Oct. 2018

[19]. M. Saeed Osman, "Uncertainty modeling for bus selection and allocation in a private transportation system," Transportation Planning and Technology, vol. 42, no. 7, pp. 714-728, Aug. 2019.

[20]. Z.-C. Li, W. H. K. Lam, and S. C. Wong, "Modeling intermodal equilibrium for bimodal transportation system design problems in a linear monocentric city," Transportation Research Part B: Methodological, vol. 46, no. 1, pp. 30-49, Jan. 2012

[21]. J. R. Mbwana and M. A. Turnquist, "Optimization Modeling for Enhanced Network-Level Pavement Management System," Transportation Research Record: Journal of the Transportation Research Board, vol. 1524, no. 1, pp. 76-85, Jan. 1996.

[22]. R. Saha, M. T. Tariq, M. Hadi, and Y. Xiao, "Pattern Recognition Using Clustering Analysis to Support Transportation System Management, Operations, and Modeling," Journal of Advanced Transportation, vol. 2019, pp. 1-12, Dec. 2019. 